\title{
JULIO CORTÁZAR GAMER: RAYUELA E SUA REPERCUSSÃO NOS LIVROS-JOGOS
}

\section{PEDRO PANHOCA DA SILVA}

RESUMO: O Livro-jogo é um híbrido textual que combina a forma ramificada de narrativa com um sistema de regras de jogos de RPG. Sua origem ainda permanece incerta, mas muitas vezes é atribuída a manifestações anteriores criadas no Reino Unido, como a aventura-solo e a ficção interativa. 0 presente trabalho busca analisar a obra Rayuela (1963), de Julio Cortázar, como parte fundamental para o desenvolvimento de livros-jogos, focando principalmente em sua estrutura textual. Será utilizado o conceito de livro-jogo de Silva (2019), bem como de estudiosos da obra de Cortázar como Arrigucci Jr (1973), entre outros. Por ter sido criado no Reino Unido, dificilmente pensar-se-ia como precursora do livro-jogo uma obra latino-americana. Entretanto, muitos elementos de Rayuela ainda hoje fazem parte da estrutura básica de qualquer livro-jogo lançado no mercado editorial. Com isso, essa obra de Cortázar, ao lado de muitas outras de escritores de origem europeia, em sua maioria, mostra ser mais do que uma narrativa experimental da periférica da literatura latino-americana. Sendo precursora de um gênero textual híbrido que conheceu grande sucesso entre os públicos leitor e gamer dos anos 1980 e 1990, é relevante analisar Rayuela em conexão com novas abordagens de estudos, mais voltadas à temática dos jogos.

PALAVRAS-CHAvE: Rayuela; Julio Cortázar; livros-jogos; América Latina.

\section{INTRODUÇÃO}

Julio Cortázar foi um dos mais importantes contistas e romancistas da literatura latino-americana do século XX. Entretanto, estudos acadêmicos não mencionam com frequência seu pioneirismo também em um gênero textual que 
ganhou destaque muitas décadas depois da publicação de Rayuela (1963), considerada sua obra mais radical (ARRIGUCCI JR, 1973, p. 27). Romance internacionalmente conhecido, no Brasil integra catálogos das principais universidades. Só no Estado de São Paulo, por exemplo, possui sete ${ }^{15}$ edições diferentes no acervo da Universidade Estadual de Campinas (UNICAMP), doze ${ }^{16}$ no acervo da Universidade Estadual Paulista (UNESP) e onze ${ }^{17}$ no acervo da Universidade de São Paulo (USP).

Ficções interativas existem desde a década de 1930, bem antes do ano de publicação de Rayuela. Além disso, apesar de ter em português o nome de um jogo, O Jogo da Amarelinha, a obra de Cortázar não propõe ao leitor um jogo de fato, pois não há como vencer ou perder durante a leitura, muito menos há um caminho mais ou menos adequado a se seguir. Isso não desqualifica o autor de Rayuela de nenhuma maneira. Sua obra não pode ser considerada de menor valor em relação a uma estrutura conhecida pelo público leitor, a partir de Consider the Consequences!, de Doris Webster e Mary Alden Hopkins, publicada em 1930;

15 Fazem parte do catálogo as edições de 1969, 1975 (ambas publicadas pela editora Sudamericana, de Buenos Aires, Argentina) e de 1986 (publicada pela editora Cátedra, de Madrid, Espanha) publicadas como Rayuela, e as edições de 1974, 1982, 1994 e 2009 (todas publicadas pela editora Civilização Brasileira, do Rio de Janeiro) publicadas como O Jogo da Amarelinha. O acervo da universidade, por vezes, apresenta mais de um exemplar do mesmo livro, variando o número de edição ou mesmo repetindo-o.

16 Fazem parte do catálogo as edições de 1969, 1976, 1978, (todas publicadas pela editora Sudamericana, de Buenos Aires, Argentina), 1980 (publicada pela editora Biblioteca Ayacucho, de Caracas, Venezuela), além de um exemplar sem data precisa (19--, edição desconhecida), publicadas como Rayuela, e as edições de 1970, 1972, 1974, 1987, 2009, 2014 e 2016 (todas publicadas pela editora Civilização Brasileira, do Rio de Janeiro) publicadas como O Jogo da Amarelinha. O acervo da universidade, por vezes, apresenta mais de um exemplar do mesmo livro, variando o número de edição ou mesmo repetindo-o. Essa listagem foi feita com base no acervo total da universidade, ignorando a distribuição das obras pelos 24 campi da instituição.

17 Fazem parte do catálogo as edições de 1966, 1968, 1969, 1972 (todas publicadas pela Editorial Sudamericana, Buenos Aires), 1984 (publicada pela Ediciones Alfaguara, Madrid), 1988 (publicada pela editora Biblioteca Ayacucho, Caracas), 1991 (publicada pela editora ALLCA, Paris), 1996 (publicada pela editora ALLCA XX, Nanterre), 2001 (publicada pela editora Bibliotex, Barcelona), publicadas como Rayuela, e as edições de 1982 e 2008 (ambas publicadas pela editora Civilização Brasileira, Rio de Janeiro) publicadas como O Jogo da Amarelinha. O acervo da universidade, por vezes, apresenta mais de um exemplar do mesmo livro, variando o número de edição ou mesmo repetindo-o. 
as autoras do que atualmente é considerado o primeiro protótipo de livro-jogo foram "redescobertas" recentemente, e sua obra ainda carece de análises e estudos profundos ${ }^{18}$.

Outras obras relacionadas às ficções interativas são Night of January 16th (1936), de Ayn Rand, que é mais uma peça interativa do que uma literatura lúdica; os livros da série TutorText: Doubledays Series (1958-1972) eram livros de cunho exclusivamente pedagógico, portanto não literários e não direcionados para o deleite do leitor; e dois contos de Jorge Luis Borges, "Exame da obra de Herbert Quain” (1941) e “O jardim dos caminhos que se bifurcam” (1941), sempre lembrados pelos apreciadores dos livros-jogos, pois são contos que trazem a ideia de uma narrativa labiríntica, ainda muito complexa e abstrata para a época. No presente artigo, adotamos a noção de livro-jogo segundo Silva (2019), quem afirma que um livro-jogo é uma narrativa lúdica ramificada dotada de um sistema de regras de RPG (fichas de personagem, uso de rolamento de dados, informações e valores quantitativos referentes a atributos de personagem etc.), cuja extensão ultrapasse 50 páginas escritas.

Dessa forma, acreditamos que Rayuela merece destaque por apresentar ao leitor uma estrutura interativa explícita e pertencer à história da literatura argentina de modo a ganhar reconhecimento internacional. A estrutura desta curiosa obra literária é, por vezes, considerada uma importante precursora dos livros hoje conhecidos como livros-jogos, além de poder ter inspirado a criação da aventurasolo, outro gênero bastante conhecido por jogadores de RPG da geração "roladora de dados" (SALDANHA; BATISTA, 2009, p. 705), de jogos em forma de texto e leitores de ficções interativas. Logo, a intenção do presente artigo é propor uma reflexão sobre como um romance de caráter experimental de origem latino-americana ganhou repercussão internacional e ajudou a criar um tipo de estrutura textual fundamental para o desenvolvimento de livros-jogos.

18 James Ryan publicou em sua página da rede social Twitter em 03/09/2017 essa "descoberta". Disponível em : <https://twitter.com/xfoml/status/904364084820193280>. 


\section{A CHARMOSA FILHA DO CAOS: ASPECTOS GERAIS DE RAYUELA}

Publicada em 1963, Rayuela provocou grande impacto internacional ${ }^{19}$, pois produziu um impressionante efeito de arrasto sobre o conjunto da obra anterior de Cortázar, bem como de outros escritores, como Jorge Luís Borges e Leopoldo Marechal (OLGUÍN; ZEIGER, 2014, p. 373). O enredo de Rayuela gira em torno de Horacio Oliveira, um boêmio argentino, e a jovem uruguaia Lucía, conhecida como "Maga". Ambos são muito diferentes entre si: Oliveira possui amplos conhecimentos artísticos e Maga nem tanto. O casal deixa a América do Sul com objetivos diferentes: Horacio deseja se encontrar, e Maga, refinar a voz. Ambos vivem graças à pequena ajuda financeira de um irmão de Oliveira em Rosário, à prestação de pequenos serviços de Oliveira como contador e aos trabalhos eventuais de baixa remuneração que Maga consegue.

O casal é membro do Clube da Serpente, um grupo de artistas que discute sobre os mais diversos assuntos, principalmente os artísticos. Um dos integrantes do clube é um misterioso escritor que vira o guru de Oliveira. Seu nome é desconhecido por todos, pois chamam-no apenas de Morelli, cuja obra é muitas vezes discutida pelos membros do grupo. Mesmo assim, o sustento da família é insuficiente, pois Maga também cuida de um filho doente chamado Rocamadour, que vive num pensionato na periferia da cidade-luz. Este filho atrapalha muito a convivência entre Oliveira e Maga, por ser uma criança que chora e fede muito, consequências de sua enfermidade. Devido ao incômodo que Oliveira sente por Rocamadour, Maga um dia deixa a casa de Oliveira. Ossip Gregorovius passa a visitá-la, o que causa certo ciúme em Oliveira. A vingança que Oliveira encontra é ter um caso com uma jovem francesa chamada Pola. Maga, sabendo da traição de Oliveira, roga que Pola contraia uma grave enfermidade, o que realmente acontece. Com isso, Maga se afoga em culpa.

\footnotetext{
19 A edição de Rayuela escolhida para o presente artigo possui dentre seus paratextos uma coletânea de cartas que atestam a grande aceitação do público leitor (positivamente ou negativamente) desse romance. Sugere-se a leitura das cartas a Ana María Barrenechea (pp. 547-548), Perla Rotzait (pp. 548-549), Paul e Sara Blackburn (p. 549), Roberto Fernández Retamar (p. 552), Paco Porrúa (pp. 553; 557-558), Amparo Dávila (p. 553), Jean Barnabé (pp. 553-556), Leopoldo Marechal (pp. 556-557), Guillermo Cabrera Infante (p. 558), Lida Aronne de Amestoy (p. 559, duas cartas) e Saúl Sosnowski (pp. 559-560). Além disso, Haroldo de Campos menciona um artigo de crítica positiva do suplemento literário do jornal Times de Londres (2019, p. 561).
} 
Morelli, o misterioso escritor é vítima de um atropelamento. Chega a ser socorrido, mas morre no hospital, sem ter seu nome revelado. Num dia de chuva, Oliveira tenta evitar o mau tempo esperando na porta de um teatro e decide esperar assistindo ao concerto de uma pianista chamada Madame Berthe Trepat. Quando retorna para sua casa, flagra Maga e Ossip ouvindo música no escuro, o que lhe faz crer que ha uma relação muito íntima - talvez sexual - entre os dois. Nessa mesma noite, mais tarde, o filho de Maga morre. Oliveira não vai ao velório nem ao enterro da criança e, quando retorna em casa, encontra apenas Ossip, que lhe avisa que passará a morar aí, já que Maga se mudou da cidade.

Depois que Babs, um dos integrantes do Clube da Serpente, discute com Oliveira sobre sua indiferença e por ele não ter apoiado Maga nesse momento trágico de suas vidas, as relações entre todos os artistas começam a ruir. Oliveira decide procurar por Maga em lugares de Paris onde os dois costumavam passear, e não a encontra. Porém, conhece Emmanuelle, uma mendiga, e os dois passam a noite regados a bebida e conversa, culminando com a sedução da maltrapilha que acaricia sexualmente e explicitamente Oliveira no local público em que eles se encontram. A polícia passa pelo local e presencia a cena, prendendo ambos e deportando Oliveira para a Argentina.

Mesmo tendo sido um amigo muito ausente para com os companheiros latino-americanos, seu amigo de longa data, chamado Traveler, e sua esposa Talita aguardam sua chegada no porto, avisados do acontecimento por uma ex-namorada de Oliveira, Gekrepten, que consegue a informação através do serviço diplomático. Amparado pelo casal e buscando se adaptar ao novo lar, Oliveira vende tecidos, mas a época de verão não favorece seus negócios. Traveler consegue um emprego para ele no circo Las Estrellas, onde o próprio casal trabalha. Devido a essa aproximação entre Traveler e Horacio, Talita começa a se apaixonar por ele, quem, por sua vez, vê nela características de Maga.

Ferraguto, o diretor do Las Estrellas, junto com sua esposa Cuca, vendem seu empreendimento e adquirem um manicômio. Com isso, Oliveira, Traveler e Talita passam a morar na clínica. Da janela do segundo andar da clínica, Oliveira percebe um jogo de amarelinha pintado no chão, e pensa ver Maga brincando nela, mas na verdade é Talita. Oliveira desce para iniciar uma conversa com ela, que tenta esconder que se sente desconfortável com ele. Tudo culmina com a ten- 
tativa de Oliveira de beijá-la. Talita o repele, volta a seu quarto e conta a seu marido o ocorrido. Traveler, no dia seguinte, vai ao quarto de Oliveira conversar, mas este, muito perturbado psicologicamente, ameaça pular da janela para se matar. Traveler tenta convencer Oliveira a não se matar e entender seu estado de saúde mental, mas Oliveira não o escuta e acaba se jogando para a morte.

Rayuela não foi mero experimentalismo de época, pois tinha a ambição de romper convenções literárias como fizeram escritores como Proust, Joyce, Woolf, Musil, Gombrowicz, só para citar alguns (BARRENECHEA apud GOLOBOFF, 2014, p. 294). A obra de Cortázar foi considerada renovadora e provocadora de ruptura (RÚSSOVICH, 2000, p. 368), mesmo pertencendo à periférica literatura latino-americana. Além disso, ela é geralmente mencionada e relacionada com os livros-jogos e das ficções interativas, como no artigo de revista de Lisboa (2008), artigo de jornal de Cantó (2018), periódicos online de Costikyan (2003, 2007), artigos acadêmicos de Gobira (2014), Pisarski (2014) e Wake (2016), capítulo de livros de Kilpiö (2018), livros de Vanderdorpe (2009), Tresca (2010), Bernal-Merino (2014), Mukherjee (2015), Fuchs; Thoss (2019), dissertação de mestrado de Stateri (2008), dissertação de doutorado de Paniagua (2011), teses de doutorado de Alves (1997), Fizek (2012), Lesnovski (2014) e Merino (2015), e até mesmo em um curso de extensão ministrado pelo professor Ricardo Ruiz ${ }^{20}$ (2018), só para citar alguns pesquisadores, o que reforça seu pioneirismo na criação desses híbridos textuais lúdicos. O próprio Cortázar defendeu a ideia de que um escritor deveria ser majestosamente criativo a ponto de não facilitar a leitura ao leitor por meio de obstáculos a serem superados e aproveitar dessa situação a fim de criar um novo espaço para o romance latino-americano (GONZÁLEZ, 200o, p. 414).

Segundo Cortez,

À diferença destas [as literaturas estrangeiras], a hispano-americana manifesta o gosto pelas formas elaboradas, obscuras e complicadas; a deformação dos modelos; a proliferação do mítico e do simbólico; o predomínio da intuição e da emoção; o tom patético e a truculência psicológica; a utilização da literatura como instrumento de luta política e pregação reformista. (CORTEZ, 1977, p. 81)

20 O curso tem o nome de "El joc etern: literatura i gamificació" e seu conteúdo programático está disponível em: <https://campusdeescritura.com/inline/ES/curso/El-joc-etern-literatura-igamificacio >. Acesso em: 18 out. 2019. 
A narrativa de Rayuela contém todos os elementos destacados por Cortez, o que faz dela um romance com a marca da América Latina, e provoca o descolamento do rótulo de mero recipiente de literatura estrangeira. Também, graças a isso, ela pode ser considerada "escorpiônica" pelo fato de que Cortázar precisou buscar o caos narrativo em uma estrutura que ainda hoje é vista como algo muito peculiar para criar a sua obra. Sem isso, Rayuela seria apenas mais um romance, pois seu diferencial está, dentre suas muitas qualidades, na própria estrutura narrativa. Cortázar precisou subverter toda a "estrutura" do romance conhecida até então para realizar seu "suicídio escorpiônico"21. Com isso, Rayuela pode ser considerado um livro anti-literário, mas não anti-romanesco, pois vale ressaltar que o gênero literário romance possibilita experimentalismos desde que foi “criado", pois em sua própria etimologia (do inglês novel e do espanhol novela) pode remeter-se a novelty ("novidade", em inglês).

\section{UM LIVRO QUE INSPIROU LIVROS-JOGOS: A ESTRUTURA TEXTUAL DE}

\section{RAYUELA}

Livros-jogos estavam longe de serem idealizados e o primeiro RPG só seria lançado dez anos depois da publicação de Rayuela. Contudo, certos aspectos do livro de Cortázar servem como parâmetro para uma aventura desse estilo. O livro se inicia com a frase "encontraria a Maga?", o que lembra muito os livros-jogos que logo de início informam o leitor-jogador sobre a missão a ser cumprida, além da presença do elemento fantástico mencionado, isto é, maga, normalmente tratada como uma feiticeira nos jogos do gênero RPG. O encontro entre Horacio e Maga no enredo do livro é algo que não pode ser consumado, e é justamente essa busca, cuja chance de fracasso é muito grande, que caracteriza uma típica missão rpgística. Num primeiro momento, parece impossível, mas por meio das escolhas certas e um pouco de sorte pode ser que aconteça o sucesso. Em livros-jogos/RPG, as missões mais recorrentes consistem em matar um dragão, saquear um castelo, resgatar um prisioneiro etc. Além disso, Horacio e Maga são seres contrários, assim como o leitor-protagonista e seu arqui-inimigo do livro-jogo. O

21 Vale ressaltar que a expressão entre aspas constitui uma metáfora popular. É sabido que o escorpião, de fato, não comete suicídio, visto que quando se encontra em situações de grande perigo o animal perde o controle de sua cauda venenosa e pode, acidentalmente, picar-se e morrer pelo próprio veneno. 
leitor-jogador também muito se parece com Horacio por ser um perseguidor, pois busca de toda forma cumprir sua missão com êxito.

Há em Rayuela uma grande marca de oralidade, tanto na voz do narrador quanto nas das personagens. Nos livros-jogos isso também não é diferente, pois o próprio livro-jogo estabelece um diálogo direto com o leitor, com verbos no imperativo, além da linguagem ser da forma mais simples e objetiva possível para parecer um narrador de RPG ambientando seu grupo na imersão do jogo, como mostra o exemplo a seguir:

230

O ser que está agora de pé à sua frente é um homem em estado de semidecomposição. Seus olhos inquietos movem-se de um lado para outro observando você. Sua língua comprida balança com um ruído sibilante. Seus dentes e unhas são pontiagudos e ele não demonstra estar com medo de sua arma. É um ESPECTRO!

$\begin{array}{lll}\text { ESPECTRO HABILIDADE } 8 & \text { ENERGIA } 7\end{array}$

Ele tem a capacidade de paralisá-lo se conseguir causar quatro ferimentos separados em você durante a batalha, por isso tome cuidado! Se você derrotá-lo, vá para 39o. Se ele matar ou paralisar você, volte para 64 (JACKSON; LIVINGSTONE, 1991, n.p.).

Porém, é justamente a dupla possibilidade de leitura de Rayuela que mais claramente pode ser a inspiração dos "RPGs solitários": a primeira é fazer uma leitura sequencial do capítulo 1 ao capítulo 56, seção do livro chamada de "Do lado de lá". A outra forma de se ler a obra é seguindo o "tabuleiro de leitura":

Este livro é, à sua maneira, muitos livros, mas é acima de tudo dois livros. O leitor está convidado a escolher uma das duas possibilidades seguintes:

O primeiro livro se deixa ler na forma comum e corrente, e termina no capítulo 56, ao pé do qual há três vistosas estrelinhas que equivalem à palavra "fim". Com isso, o leitor dispensará, sem remorsos, o que vem depois.

O segundo livro se deixa ler começando pelo capítulo 73 e depois na ordem indicada ao pé de cada capítulo. Em caso de confusão ou esquecimento, basta consultar a seguinte lista: 


$$
\begin{aligned}
& 73-1-2-116-3-84-4-71-5-81-74-6-7-8-93-68-9-104- \\
& 10-65-11-136-12-106-13-115-14-114-117-15-120-16-137-17 \\
& -97-18-153-19-90-20-126-21-79-22-62-23-124-128-24- \\
& 134-25-141-60-26-109-27-28-130-151-152-143-100-76-101 \\
& -144-92-103-108-64-155-123-145-122-112-154-85-150-95- \\
& 146-29-107-113-30-57-70-147-31-32-132-61-33-67-83- \\
& 142-34-87-105-96-94-91-82-99-35-121-36-37-98-38-39 \\
& -86-78-40-59-41-148-42-75-43-125-44-102-45-80-46- \\
& 47-110-48-111-49-118-50-119-51-69-52-89-53-66-149-54 \\
& -129-139-133-140-138-127-56-135-63-88-72-77-131-58- \\
& 131
\end{aligned}
$$

Com o objetivo de facilitar a rápida localização dos capítulos, a numeração vai se repetindo no alto das páginas correspondentes a cada um deles (CORTÁZAR, 2019, p. 7 , grifos do autor).

\section{Cortázar visava com essas duas formas de leitura transformar seu próprio leitor no único e verdadeiro personagem da narrativa, cúmplice e participativo (GOLOBOFF, 2014, p. 295), pretensão essa seguida à risca pelos livros-jogos, como no exemplo do pioneiro livro-jogo The Warlock of Firetop Mountain ${ }^{22}$ (1982):}

O Feiticeiro da Montanha de Fogo é um tipo diferente de livro. Além do livro propriamente dito, você também precisará de dois dados, de um lápis e de uma borracha. Então, armado com estes instrumentos, você poderá se tornar o herói de uma perigosa aventura para descobrir o tesouro oculto do Feiticeiro. O tesouro está escondido no fundo de uma caverna subterrânea que você terá que explorar, povoada por uma variedade de monstros subterrâneos que você terá que enfrentar e matar - ou morrer na tentativa. Em parte um romance, com sua história emocionante, e em parte um jogo, com seu elaborado sistema de combate, este livro traz muitas aventuras dentro dele para você. Cada página apresenta desafios diferentes, e as decisões que você tomar o levarão a diferentes caminhos e diferentes batalhas. Talvez você se perca no labirinto, veja sua força ser minada por uma medonha Criatura, morra em uma batalha com os Orcas ou caia diante de um dos seres dentre os muitos que guardam as criptas do tesouro do feiticeiro. Ou, então, com coragem, determinação e uma boa dose de sorte, talvez você sobreviva a todas as armadilhas

22 Optou-se por utilizar a citação de sua tradução em português. 
e batalhas até as câmaras interiores do domínio do Feiticeiro, onde está escondido

o tesouro. Magia e monstros são reais como a própria vida nesta caça ao tesouro

de capa e espada que o deixará enfeitiçado por horas a fio! (JACKSON; LIVINGSTONE, 1991, n.p., grifos nossos)

A explicação de que o objeto a ser consumido é o livro e que há nele elementos lúdicos (aspectos de jogo) está presente na introdução de ambos os livros. Essa técnica de situar o leitor para que exerça a leitura de forma "correta" também foi uma prática seguida por outras séries de livros-jogos que surgiram devido ao sucesso da primeira série.

Em Rayuela, as seções "Do lado de lá" (capítulos de 1-36) e "Do lado de cá" (capítulos de 37-56) funcionam como leitura obrigatória, caso o leitor deseje conhecer "o primeiro livro", através da leitura sequencial. Caso opte por conhecer o "segundo livro", o leitor deve acrescentar à sua leitura a seção "De outros lados (Capítulos prescindíveis)" às duas seções precedentes, seguindo o roteiro do "Tabuleiro de leitura", promovendo assim a leitura não sequencial. A "primeira Rayuela" corresponde, num livro-jogo, às referências obrigatórias, termo que, em livros-jogos, remete às caixas de hipertextos que formam sua narrativa lúdica. Trata-se de partes centrais da narrativa-jogo que o leitor-protagonista não pode evitar durante qualquer percurso narrativo traçado, como portos de passagem da aventura. Já a "segunda Rayuela" representa as referências dispensáveis da narrativa-jogo, como escolhas malfeitas, bônus, facilidades ou dificuldades que interferem de forma positiva ou negativa no curso da narrativa do leitorprotagonista.

Seus capítulos são breves e muito trabalhados, assim como as referências dos livros-jogos, que precisam dar conta de explorar o cenário, a ação, a imersão do leitor-jogador, as opções de prosseguimento narrativo e pensar no loop ${ }^{23}$ atrelado à coerência da narrativa de um modo de leitura ao outro. Assim como há

23 Segundo Silva (2019, p. 131), "muito comum em livros-jogo e ficções interativas, mas raramente encontrado em leituras lineares, um loop é quando um caminho faz o leitor(-jogador) retornar a uma seção já lida. Devido a falhas de revisão e playtests, dependendo da escolha, o loop em determinado livro pode ser infinito". Quando um leitor finaliza a leitura do "primeiro livro" de Rayuela (capítulos de 1 a 56) e começa a leitura do "segundo livro", os 56 primeiros capítulos entrelaçados aos outros (de 57 a 155) são relidos, o que possibilita diferentes interpretações da narrativa. (AARSETH, 1997, p. 19). 
capítulos que possuem um certo grau de autonomia e destaque na obra, nos livros-jogos algumas cenas também o são, como por exemplo algumas referências primordiais para a conclusão da narrativa com sucesso, as quais podem oferecer ao leitor-jogador um item indispensável para o cumprimento de sua missão, ou o triunfo sobre o grande inimigo final, geralmente encontrado nas referências finais do livro-jogo.

Rayuela parece até ser uma narrativa mais “justa” do que um livro-jogo por não possuir o radicalismo da instant death ${ }^{24}$, já que não havia sido pensada para isso, e possuir, talvez, a dose perfeita do loop. Tais elementos quando excessivos prejudicam o deleite do leitor-jogador por situá-lo num ciclo vicioso de escolhas ou mesmo de acabar de forma brusca com tudo o que havia construído até certo momento.

Com o surgimento do livro-jogo surgiu na Inglaterra, como se convém atribuir, assim como as principais séries de todos os tempos Fighting Fantasy (19821995), Lone Wolf (1984-1998), Sorcery! (1983-1985), só para citar algumas; e a primeira série de ficção interativa best seller, a Choose Your Own Adventure (1979-1998), ter sido criada nos Estados Unidos, houve grande predomínio da publicação desses livros interativos no idioma inglês. O fato de Cortázar ser um autor em língua espanhola e ser latino-americano (argentino), o que o tira do eixo Estados Unidos-Europa, pode ter dificultado ainda mais a difusão de Rayuela nos países de língua inglesa em seu tempo, embora hoje a obra possua tradução para diversos idiomas.

Em Rayuela conflitos sobre onde e como estar, bem como alternativas entre Europa e América são explícitos (GOLOBOFF, 2014, p. 291). Tais questionamentos, embora não sejam tão profundos e complexos, são a essência de uma narrativa-jogo, ao oferecer ao leitor-jogador possibilidades de continuidade narrativa por meio de perguntas apelativas:

\section{[Referência] 4}

\footnotetext{
24 Recurso comum em livros-jogos, a "morte instantânea” é a pior escolha dentre as muitas referências que um leitor-jogador pode fazer durante sua aventura. Como o próprio nome diz, ela explica como e por que o leitor-protagonista morre na aventura, resultando no fim trágico daquela leitura-jogo e forçando-o a reiniciar a aventura com a consciência de que aquele ponto da narrativa precisará ser evitado caso ele queira obter sucesso na próxima tentativa de triunfo.
} 
Você se encontra em um corredor que vai do norte para o sul. Para o norte, a passagem vira para leste alguns metros à frente. Se quiser investigar, vá para [a referência] 46. Para o sul, a passagem também vira para o leste. Vá para [a referência] 332, se quiser ir para o sul.

(JACKSON; LIVINGSTONE, 1991, n.p.)

Desta forma, o leitor-jogador sempre precisa refletir antes de fazer suas escolhas, ao passo que a narrativa se bifurca (ou trifurca), situando-o em novas situações de reflexão e escolha.

\section{CONSIDERAÇÕES FINAIS}

Rayuela é mais que um romance não linear, pois é a mais radical reflexão sobre a própria (des)estrutura narrativa, cuja extremidade foi ainda mais radicalizada pelos inventores do livro-jogo, ao oferecer ao leitor-jogador inúmeras possibilidades de leitura, não só as duas de Cortázar. Demonstrou ser mais do que um experimentalismo de sua época, pois conheceu grande repercussão no momento de sua publicação e depois de seu lançamento. Embora Cortázar seja uma referência mais importante na contracultura e no pós-modernismo após a década de 60 do que na origem dos livros-jogos, leitores-jogadores que entram em contato com o romance se impressionam com o pioneirismo de Cortázar em relação à estrutura textual ramificada e quanto à evolução da estrutura de 1963 até os

dias atuais. É um livro muito interessante, particularmente pela descrição romantizada dessa existência boêmia de um imigrante na França. O aspecto de livrojogo torna a leitura mais interativa dando ao leitor uma certa ideia de escolha e autonomia, mas não tem tanto efeito prático na narrativa, transparecendo até a ideia da falsa escolha.

Provavelmente, ávidos leitores de Cortázar preferirão seus contos, mas Rayuela possui outros méritos, como procurou-se abordar neste artigo, e dificilmente jovens leitores do final do século XX e início do XXI se interessariam por uma obra tão complexa. Eles preferem os livros-jogos por possuírem um enredo simplório e mais interativo, mais adequados para sua maturidade. Porém, uma das consequências dos livros-jogos pode ser justamente instigar seus leitores-jogadores a buscarem leituras mais complexas e partir para ficções interativas, livros interativos, mais "livros" do que "jogos", o que traz um resultado muito 
proveitoso para a bagagem literária dos leitores. Dessa forma, autores como Borges e Cortázar funcionariam como autores de ficções interativas mais maduros, algo como "livros-jogos para leitores experientes" ou "leitores-aventureiros veteranos".

Portanto, Cortázar pode ser visto como um importante precursor do livrojogo. Por meio de sua Rayuela, ele merece maior divulgação e análise, tanto no exterior quando na própria América Latina. Seu romance inclui, entre outros elementos, níveis conflitivos como o pessoal, o literário, o nacional e o latino-americano, trazendo de forma interativa temas como os deveres e as funções do escritor (GOLOBOFF, 2014, p. 293). Há que se considerar que em Rayuela, Cortázar consegue mostrar como o seu jogo (da amarelinha) se aproxima da vida, enquanto os livros-jogos promovem o papel inverso, ou seja, transformar a vida do leitor-protagonista, imerso na narrativa de aventura interativa, em jogo (de RPG). Por outro lado, tanto Rayuela como qualquer livro-jogo produzido desde 1982 até o mais recente lançamento, dizem muito sobre a própria vida de leitores, jogadores, personagens e homens: a vida de nenhum desses seres, ficcionais ou reais, é linear, sequencial, programada nem previsível. Na literatura e na vida, desta forma, são feitas de escolhas. O jogo da amarelinha bifurca-se e, ao se escolher uma casa, abre-se mão da outra. Deve-se ir do "inferno" ao "céu", do lado de "cá" para o lado de "lá" ou vice-versa. O próprio ato de se desenhar o jogo da amarelinha no chão já é uma escolha: por que em uma rua e não na outra? Se o jogo for pintado a tinta se gasta, mas se a tinta não se gastar não haverá jogo a ser usufruído.

Para além de buscar a origem do livro-jogo em algum lugar da Europa, os estudos acadêmicos poderiam partir da obra de Cortázar para direcionar pesquisas na área da literatura lúdica e dos games. A partir dessa obra incompreensivelmente segregada, não contida nos conjuntos Europa e Estados Unidos, e a partir da análise de seu corpus numa maior dimensão, poderiam ser quebradas barreiras que a própria literatura se impõe, separando seus filhos por escolas literárias, espaços geográficos, períodos históricos e assuntos explorados.

\section{REFERÊNCIAS}

AARSETH, Espen J. Cybertext: perspectives on Ergodic Literature. Maryland: John Hopkins University Press, 1997. 
ALVES, Maria Angélica. Tudo o que o seu mestre mandar: a figuração do narrador e do leitor nos textos interativos. 1997. 225 f. Tese (Doutorado em Literatura Brasileira). Universidade Federal do Rio de Janeiro, Rio de Janeiro.

ARRIGUCCI JR., Davi. O escorpião encalacrado: a poética da destruição em Julio Cortázar. São Paulo, SP: Perspectiva, 1973.

BERNAL-MERINO, Miguel Á. Translation and Localisation in Video Games: Making Entertainment Software Global. Abingdon: Routledge, 2014.

CAMPOS, Haroldo de. 0 jogo de amarelinha. In: CORTÁZAR, Julio. 0 jogo da amarelinha. Trad. Eric Nepomuceno. 1. ed. São Paulo: Companhia das Letras, 2019. pp. 561-566.

CANTÓ, Pablo. La historia de 'Elige tu propia aventura', el formato que probará 'Black Mirror'. 2018. Disponível em: <https://verne.elpais.com/verne/2018/10/02/articulo/1538485993_575380.html>. Acesso em 20 out 2019.

CORTÁZAR, Julio. 0 jogo da amarelinha. Trad. Eric Nepomuceno. $1^{a}$ ed. São Paulo: Companhia das Letras, 2019.

CORTEZ, Irlemar Chiampi. A imagem da América. 1977. Disponível em: <https://www.revistas.usp.br/linguaeliteratura/article/download/115810/113324>. Acesso em 02 Nov 2019.

COSTIKYAN, Greg. Where Stories End and Games Begin. 2003. Disponivel em: <http://papers.cumincad.org/data/works/att/b8bc.content.pdf>. Acesso em 24 out 2019.

. Games, Storytelling, and Breaking the String. 2007. Disponível em: <https://electronicbookreview.com/essay/games-storytelling-and-breaking-the-string/>. Acesso em: 18 out 2019.

FIZEK, Sonia. Pivoting the Player: A Methodological Toolkit for Player Character Research in Offline Role-Playing Games. 2012. 286 f. Tese (Doutorado). Bangor University, Bangor.

FUCHS, Michael; THOSS, Jeff. Intermedia Games - Games Inter Media: Video Games and Intermediality. Internet: Bloomsbury Academic, 2019.

GOBIRA, Pablo. Um estudo preliminar sobre o livro jogo digital como um gênero. SBC - Proceedings of SBGames 2014, 2014, pp. 61-66. Disponível em: <www.sbgames.org/sbgames2014/files/papers/art_design/full/A\&D_Full_Um\%20estudo\%20preliminar.pdf>. Acesso em: 22 out 2019. 
GOLOBOFF, Mario. Una literatura de puentes y pasajes: Julio Cortázar. In: JITRIK, Noé.

Historia crítica de la literatura argentina: El oficio se afirma. Tomo 9 (dirigido por Sylvia Saítta). 2.ed. Buenos Aires: Emecé, 2014. pp. 277-304.

GONZÁLEZ, Horacio. El boom: rastros de una palabra en la narrativa y la crítica argentina. In: JITRIK, Noé. Historia crítica de la literatura argentina: La narración gana la partida. Tomo 11 (dirigido por Elsa Drucaroff). 1.ed. Buenos Aires: Emecé, 2000. pp. 405-430.

JACKSON, Steve; LIVINGSTONE, Ian. O Feiticeiro da Montanha de Fogo. Trad. Marco Antônio Esteves da Rocha. Rio de Janeiro: Marques Saraiva, 1991.

KILPIÖ, Juha-Pekka. Explorative exposure: media in and of Mark Z. Danielewski's House of Leaves. In: HAX, Arnoldo; OLAVARRÍA, Lionel (Org.). Reading Today. Internet: UCL Press, 2018, p. 57-70.

LESNOVSKI, Ana Flávia Merino. Uma experiência paradigmática: jogos e tensões no encontro entre a narrativa e a interatividade em forma audiovisual e eletrônica. 2014. 295 f. Tese (Doutorado em Comunicação Social). Pontifícia Universidade Católica do Rio Grande do Sul, Porto Alegre.

LISBOA, Pedro. Leitor e herói: a era dourada dos livros-jogo. 2018. Disponível em: $<$ https://fotocopiasedragoes.files.wordpress.com/2019/01/pedrolisboa_bang25_outubro2018.pdf>. Acesso em 22: out 2019.

MERINO, Francisco Alexandre Lopes Figueiredo. Narrativas Transmediáticas: 0 lugar do cinema. 2015. 302 f. Tese (Doutorado em Ciências da Comunicação). Universidade da Beira Interior, Covilhã.

MUKHERJEE, Souvik. Video Games and Storytelling: Reading Games and Playing Books. Londres: Palgrave Macmillan, 2015.

OLGUÍN, Sergio; ZEIGER, Claudio. La narrativa como programa: compromiso y eficacia. In: JITRIK, Noé. Historia crítica de la literatura argentina: La irrupción de la crítica. Tomo 10 (dirigido por Susana Cella). $2^{a}$ ed. Buenos Aires: Emecé, 2014. pp. 359-375.

PANIAGUA, Maya Zalbidea. Reading and teaching gender issues in electronic literature and new media art. 2011. 341 f. Dissertação (Doutorado em Inglês). Universidad Complutense de Madrid, Madrid.

PISARSKI, Mariusz. Bruno Schulz - Digitally. The Internet Gamebook Idol and the Future of Schulz Adaptations on the Computer Screen. Trad. Timothy Williams. 2014. Disponível em: <http://czaskultury.pl/en/wp-content/uploads/2017/- 
02/MPisarski_BrunoSchulzDigitally_CzasKultury_1_2014.pdf>. Acesso em: 24 out 2019.

RÚSSOVICH, Alejandro. Gombrowicz en el relato argentino. In: JITRIK, Noé. Historia crítica de la literatura argentina: La narración gana la partida. Tomo 11 (dirigido por Elsa Drucaroff). 1ª ed. Buenos Aires: Emecé, 2000. pp. 361-376.

SALDANHA, Ana Alayde; BATISTA, José Roniere Morais. A Concepção do Role-Playing Game (Rpg) em Jogadores Sistemáticos. Psicologia Ciência e Profissão, João Pessoa, v. 4, n. 29, 2009. pp. 700-717.

SILVA, Pedro Panhoca da. O livro-jogo e suas séries fundadoras. 2019. 326 f. Dissertação (Mestrado em Letras) - Universidade Estadual Paulista (UNESP), Faculdade de Ciências e Letras, Assis, 2019.

STATERI, Julia. Videogame: como mídia da construção narrativa. 2008. 137 f. Dissertação (Mestrado em Educação, Arte e História da Cultura). Universidade Presbiteriana Mackenzie, São Paulo.

TRESCA, Michal J. The Evolution of Fantasy Role-Playing Games. Jefferson: McFarland \& Company, 2010.

VANDERDORP, Christian. From Papyrus to Hypertext: Toward the Universal Digital Library. Champaign: University of Illinois Press, 2009.

WAKE, Paul. Life and death in the second person: Identification, empathy and antipathy in the gamebook. Narrative, n. 24, 2016, pp. 1-40. Disponivel em: <https://e-space.mmu.ac.uk/612211/2/Life\%20and\%20Death-\%20NARRATIVE\%20revisions\%20(Wake)\%2011\%209\%202015.pdf>. Acesso em: 22 out 2019. 